\title{
Prevention of Fatal Opioid Overdose
}

\author{
Leo Beletsky, JD, MPH, Josiah D. Rich, MD, MPH, and Alexander Y. Walley, MD, MSc \\ Northeastern University School of Law and Bouvé College of Health Sciences, Boston, \\ Massachusetts (Mr Beletsky); University of California, San Diego, School of Medicine, La Jolla \\ (Mr Beletsky); Brown Medical School and The Miriam Hospital, Providence, Rhode Island (Dr \\ Rich); and Boston University School of Medicine and Boston Medical Center, Boston (Dr Walley).
}

\begin{abstract}
Opioid overdose is a burgeoning public health crisis, accounting for at least 16000 deaths annually in the United States. ${ }^{1}$ Opioid overdose occurs across sex, ethnic, age, and geographic strata and involves both medical and nonmedical opioid use. To date, federal government response has focused primarily on monitoring and securing the drug supply. ${ }^{1}$ This Viewpoint suggests various steps necessary to support a more comprehensive approach.
\end{abstract}

During the time it typically takes some overdoses to turn fatal, it is possible to reverse the respiratory depression and other effects of opioids with the antagonist naloxone. Community-based organizations, health care institutions, and local and state agencies have begun to train and equip potential nonmedical bystanders to recognize and reverse overdose events using first aid techniques and emergency supplies of naloxone. ${ }^{2,3}$ As the number of such initiatives has increased, the 53000 program trainees have tracked more than 10000 reports of overdose rescues in the United States. ${ }^{2}$ These efforts have targeted drug users (syringe access programs, drug treatment centers, correctional facilities), ${ }^{1}$ physicians (to "coprescribe" naloxone along with opioids), ${ }^{4}$ and first responders (ie, fire and police). ${ }^{3}$ The concept has also gained traction among policy makers, including the Office of the National Drug Control Policy and professional organizations. ${ }^{5}$

Despite the mounting supportive evidence, the number of these programs remains limited in many communities with elevated rates of fatal overdose. ${ }^{2}$ Multiple barriers limit the diffusion of this innovation: the price of naloxone has sky-rocketed in the context of a severe shortage; few prescribers are aware of and are willing to facilitate overdose prevention education and naloxone access; funding for program activities and evaluation research

\footnotetext{
(C)2012 American Medical Association. All rights reserved.

Corresponding Author: Leo Beletsky, JD, MPH, Northeastern University School of Law and Bouvé College of Health Sciences, Boston, Massachusetts, 400 Huntington Ave, Boston, MA 02115 (1.beletsky@ neu.edu)..

Funding/Support: Mr Beletsky is supported by award R37DA019829 from the National Institute on Drug Abuse (S. Strathdee, principal investigator [PI]). Dr Rich is supported by awards 5K24DA022112 and 1R21DA029201 from the National Institute on Drug Abuse and by grant P30AI042853 from the National Institute of Allergy and Infectious Diseases. Dr Walley is the Medical Director of the Massachusetts Department of Public Health Opioid Overdose Prevention Pilot Program and is supported by awards R25-DA13582 and R01DA032082 (J. Samet, PI) from the National Institute on Drug Abuse and award U01AA11003 (R. Saitz, PI) from the National Institute on Alcohol Abuse and Alcoholism.

Conflict of Interest Disclosures: All authors have completed and submitted the ICMJE Form for Disclosure of Potential Conflicts of Interest and none were reported.

Role of the Sponsors: The sponsors had no role in design, preparation, review, approval, or decision to publish this article.

Disclaimer: The content of this article is solely the responsibility of the authors and does not necessarily represent the official views of the National Institute on Drug Abuse, the National Institute on Alcohol Abuse and Alcoholism, the National Institutes of Health, the Massachusetts Department of Public Health, or the Substance Abuse and Mental Health Services Administration.
} 
remains sparse; and the Food and Drug Administration (FDA)-approved formulation of naloxone is suboptimal for out-of-hospital use.

In April 2012, an interagency hearing on naloxone access was convened by the FDA and brought together practitioners, regulators, researchers, and people personally affected by overdose. Although the meeting underscored numerous regulatory hurdles, decisive action is necessary to advance overdose prevention programs beyond the proof-of-concept phase (Table).

The FDA must ensure that adequate supplies of naloxone are available to meet the increasing demand. Like many sterile injectable products, naloxone is in chronic shortage. Most naloxone programs experience challenges in obtaining naloxone because of cost increases or suppliers' inability to fill orders. ${ }^{1}$ As existing programs scale up and more jurisdictions adopt these measures, federal action can help expand naloxone supply, such as by fast-tracking importation licenses.

Health care practitioners are optimally positioned to facilitate opioid overdose prevention. Equipping clinicians and providing incentive for them to screen patients for overdose risk and to educate patients, their families, and caregivers about recognizing and responding to overdoses is an important step, alongside community-based education about opioid overdose and naloxone distribution. Explicitly integrating overdose prevention, including naloxone coprescription, into the FDA-industry cooperative strategy for evaluation and mitigation of opioid risk also could be helpful. ${ }^{4}$

Clinicians may be unclear about legal risks associated with prescribing naloxone ${ }^{6}$ and may be concerned about the possibility of facilitating risky drug use ${ }^{6}$; yet there is no evidence of such disinhibition. ${ }^{7}$ Prescribing naloxone to manage opioid overdose is consistent with its FDA-approved indication, precipitating no increased liability as long as prescribers adhere to general rules of professional conduct. ${ }^{7}$ Some states have passed laws indemnifying clinicians from risk of malpractice lawsuits perceived to arise from prescription of naloxone. Others have introduced Good Samaritan laws shielding lay bystanders and persons experiencing overdose from possible civil liability (flowing from providing first aid) and criminal drug charges when 911 is called. ${ }^{7}$ Using evidence-based model legislation, federal coordination can help disseminate these legal protections to encourage clinician engagement, lay responder rescue, and help-seeking.

In out-of-hospital settings, the administration of injectable drugs carries the risk of needlestick injury and presents logistical barriers, such as the absence of a sterile syringe and delay inpreparation. ${ }^{3}$ FDA action is needed to fast-track approval of naloxone delivery systems that are safe and user-friendly for nonmedical responders. Administration of intranasal naloxone via aftermarket nasal atomizers is an "off-label" system increasingly used by outof-hospital emergency medical personnel and bycommunity-based programs. ${ }^{3}$ The lack of FDA approval limits the implementation of intranasal formulations and devices: nasal atomizers are difficult to stock and seldom covered by insurance. FDA approval of intranasal naloxone is predicated on research demonstrating such a formulation to be "substantially equivalent" to the current formulation. Federal funding is needed to clear this hurdle because naloxone is an off-patent, generic medication not widely considered to be a promising investment by major pharmaceutical companies. Use of anautoinjector-a safe and effective method for delivery of epinephrine-represents another alternative that would require FDA approval.

Federal agencies are uniquely situated to address national public health crises through increasing awareness, funding, and coordinated action. Community-based organizations, state and local health departments, and professional societies have taken the lead in 
developing, implementing, and publicizing overdose education and naloxone distribution as a component in a comprehensive response to this veritable epidemic. ${ }^{5}$ The federal government should actively support research and programmatic action on overdose education and naloxone access.

\section{REFERENCES}

1. Centers for Disease Control and Prevention (CDC). CDC grand rounds: prescription drug overdoses —a U.S. epidemic. MMWR Morb Mortal Wkly Rep. 2012; 61(1):10-13. [PubMed: 22237030]

2. Centers for Disease Control and Prevention (CDC). Community-based opioid overdose prevention programs providing naloxone-United States, 2010. MMWR Morb Mortal Wkly Rep. 2012; 61(6): 101-105. [PubMed: 22337174]

3. Doe-Simkins M, Walley AY, Epstein A, Moyer P. Saved by the nose: bystander-administered intranasal naloxone hydrochloride for opioid overdose. Am J Public Health. 2009; 99(5):788-791. [PubMed: 19363214]

4. Albert S, Brason FW II, Sanford CK, et al. Project Lazarus: community-based overdose prevention in rural North Carolina. Pain Med. 2011; 12(suppl 2):S77-S85. s2. [PubMed: 21668761]

5. AMA Adopts New Policies at Annual Meeting; American Medical Association; Jun 19. 2012 website. http://www.ama-assn.org/ama/pub/news/news/2012-06-19-ama-adopts-new-policies.page

6. Beletsky L, Ruthazer R, Macalino GE, et al. Physicians' knowledge of and willingness to prescribe naloxone to reverse accidental opiate overdose. J Urban Health. 2007; 84(1):126-136. [PubMed: 17146712]

7. Burris S, Beletsky L, Castagna C, et al. Stopping an invisible epidemic: legal issues in the provision of naloxone to prevent opioid overdose. Drexel Law Rev. 2009; 1(2):273-340. 


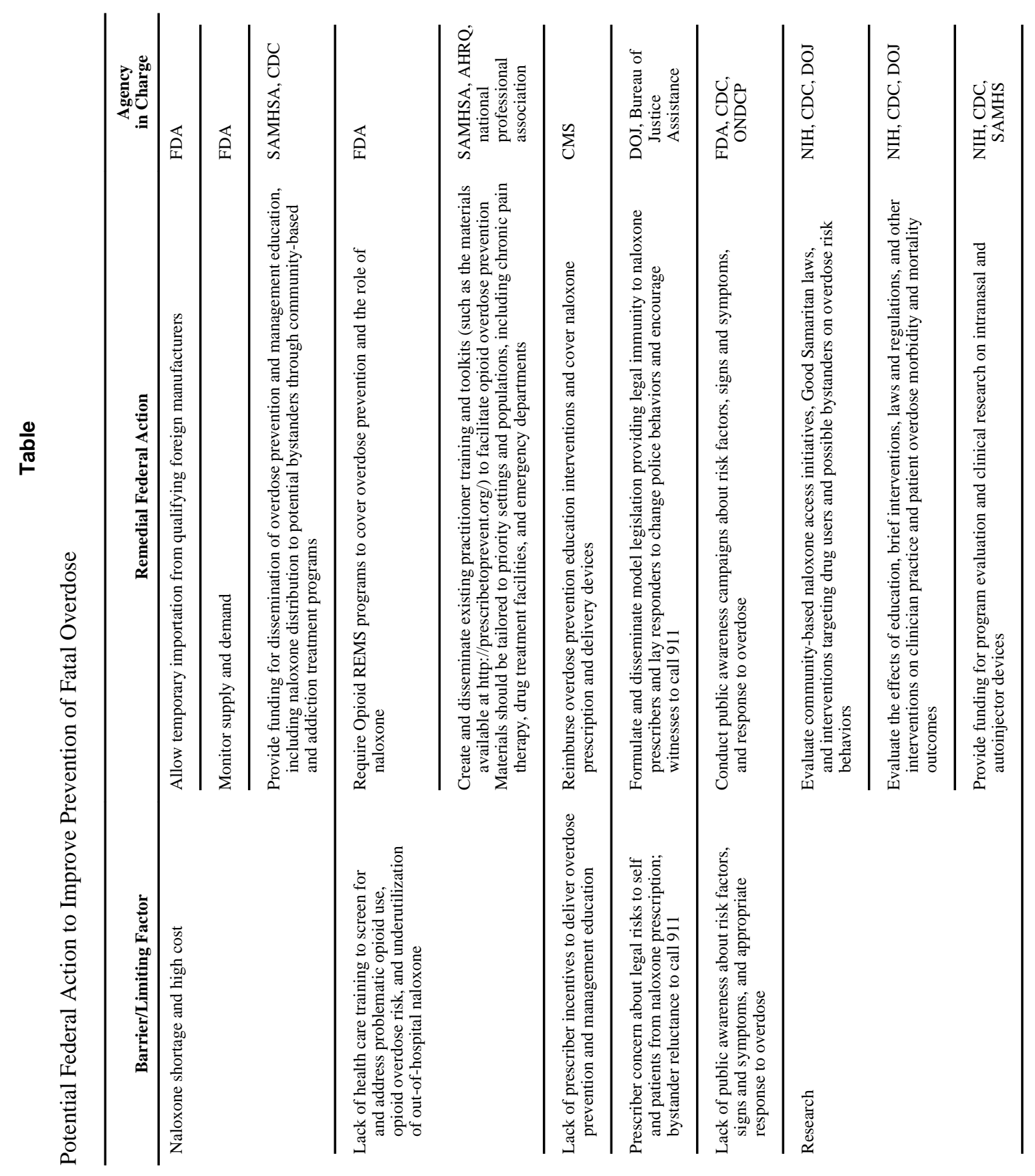




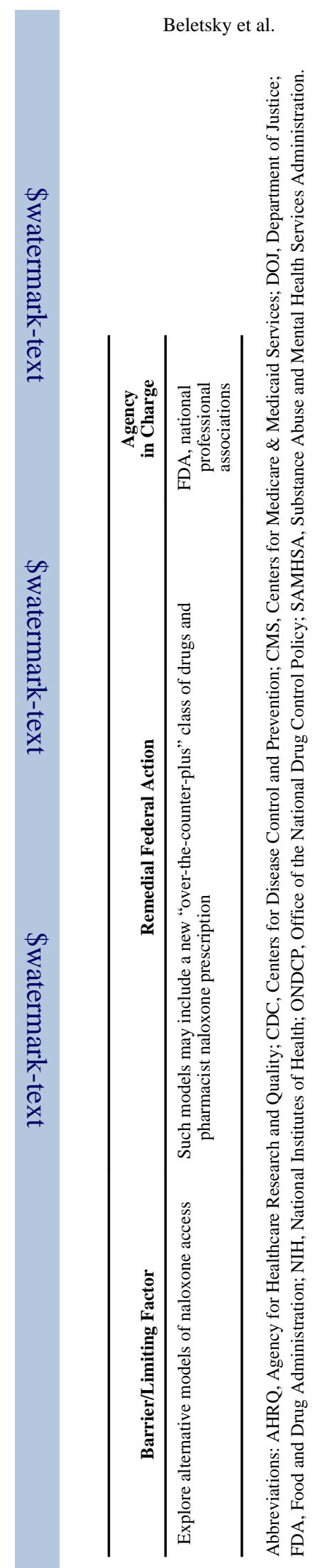

Page 5

JAMA. Author manuscript; available in PMC 2013 January 22 